\title{
Unha proposta de reflexión e avaliación de libros infantís musicados en galego
}

\section{A reflective and assessment proposal for children's musical books in Galician}

\author{
Lucía Casal de la Fuente \\ Universidade de Santiago de Compostela
}

\begin{abstract}
Resumo
$\mathrm{Na}$ Comunidade Autónoma de Galicia deuse recentemente unha crecente oferta cultural musical en galego para as nosas crianzas: observámolo na programación dalgunhas bibliotecas, centros socioculturais, colexios, concellos, festivais, etc.; así como nas propostas musicais que saen ao mercado. Analizado diverso material producido, en numerosas ocasións en formato libro-CD, detectáronse certos descoidos en canto á adecuación lingüística, de edición ou de contido. Neste artigo, e en base a esta análise, achégase un protocolo de autoavaliación, que puidera orientar na reflexión antes da edición; e establécense o que poderían ser as bases dun hipotético comité avaliador de libros musicados infantís en galego. Palabras clave: libro infantil, avaliación, material didáctico, educación musical, lingua galega.
\end{abstract}

\begin{abstract}
An increasing musical offer in Galician for children has recently flourished in the Autonomous Community of Galicia: it can be appreciated in the programmes of some libraries, sociocultural centres, schools, city councils, music festivals, etc.; as well as in the musical proposals that come to market. After analysing diverse material produced, in numerous occasions in book + CD format, certain careless mistakes have been detected, regarding linguistic, edition or content adequacy. In this article, and on the basis of this analysis, we bring a self-evaluation protocol that could guide authors in reflecting before editing; and the basis of the establishment of a hypothetical evaluation committee for children's musical books written in Galician.

Keywords: children's book, evaluation, teaching material, music education, Galician language.
\end{abstract}

\section{Introdución}

Cada vez máis profesorado de Educación Infantil, Primaria ou Secundaria, músicas e músicos, e incluso persoal investigador e docente de universidade, elaboran propostas que unen literatura e música en galego dirixida á infancia, resultando maioritariamente compartidos coa comunidade a través da publicación dun libro-CD. Estes esforzos son de gran recoñecemento, por ter sido pioneiros nestas esferas. e son acollidos calorosamente na sociedade galega. Algunhas persoas que presentan este tipo de traballos, especialmente as docentes, están formadas e preocupadas por dar un contido pedagóxico e didáctico non puramente musical ás súas achegas. Buscan incidir coas súas composicións noutros aspectos básicos a traballar na etapa infantil, conformando proxectos que integran a aprendizaxe e o ensino de todas as linguaxes (expresiva, musical, corporal, verbal, non verbal, etc.) cos contidos propios da Educación Infantil, que se concretan no seu currículo. Por exemplo: as cores, os sons, os ritmos, os trabalinguas, os ditos e refráns, a dramatización, a psicomotricidade, a educación afectiva, as partes do corpo, os animais, etc.

Non obstante, olladas reflexivas a estes materiais suxiren erros lingüísticos no galego normativo, descoido no uso da linguaxe inclusiva, ou voces e músicas cuxas tesituras están alongadas dos fundamentos da Educación Musical na infancia. A relevancia de escribir este artigo baséase na responsabilidade social da edición de libros musicados infantís e en galego, baixo a necesidade dúas premisas:

Dar unha mirada crítica á oferta editorial dispoñible.

Abrir unha canle de debate sobre a calidade e a avaliación dos libros musicados en galego orientados ao público infantil.

Aínda que na Comunidade Autónoma de Galicia contamos con grupos de investigación específicos que estudan e avalían materiais didácticos, como o grupo Cavila, non dispoñemos dun comité avaliador centrado en libros musicados en galego para a infancia, e descoñécese ata o momento a existencia da publicación dun protocolo específico estandarizado de avaliación de libros musicados en galego para a etapa infantil. Co ánimo de velar pola calidade destes, suxírense neste texto unha proposta reflexiva e outra avaliativa:

A primeira reúne unha serie de criterios xerais de cara a orientar a reflexión antes da publicación. Estes criterios poderían ser útiles dobremente para axudar á mellora da edición de libros musicados infantís e á cavilación previa antes da publicación para, nun futuro, poder evocar o camiño cara a un hipotético protocolo de avaliación estandarizado.

A segunda versa sobre a proposta de creación dun hipotético comité avaliador de libros musicados en galego para o público infantil.

\section{Método}

\section{Procedemento}

En primeiro lugar deuse unha ollada á oferta de libros musicados en galego actuais. Léronse con detemento os textos, interpretáronse os subtextos, analizáronse as imaxes, etc. De aquí extraéronse as categorías dos elementos máis susceptibles de mellora e buscouse 
información sobre avaliación de libros (literarios, informativos...), así como sobre comités de valoración e/ou avaliación de libros. Tendo en conta algunhas das categorías que presento e outras que puiden extraer da análise documental da literatura consultada, elaborei a proposta.

\section{Resultados}

\section{Con respecto á autoavaliación}

Ante a importancia e necesidade de conservar as composicións que se fan e perpetualas, coa súa transferibilidade social debida -incluso en vistas á difusión para que outras profesionais poidan facer uso destes traballos na súa profesión-, xorde a necesidade de pensar un formato de edición para rescatar e inmortalizar un proxecto musical. É dicir: elaborar un libro musicado, normalmente cun agregado (como un disco) no que poder escoitar e desfrutar a música que acompaña aos textos ou cancións propiamente ditas. Neste punto xorden dúas cuestións:

1)Cal é a "mellor" forma de plasmar as miñas composicións en papel e en formato dixital?

2)Como autoavaliar o traballo realizado? En que teño que pensar para mellorar o meu proxecto?

Para musicar un libro (tanto se trate de poemas como de narracións musicadas) debemos ter moi en conta o destinatariado e diferenciar os niveis de lectura da etapa infantil, así como as posibilidades pedagóxico-musicais. De acordo con Lluch e Chaparro (2007), no primeiro ciclo (dende o nacemento ata os tres anos) debemos ter presente que as crianzas len a través de quen as coida. Cancións, contos, xogos corporais, rimas e poesías son os primeiros textos cos que se achegan á lectura. Encántalles explorar libros ilustrados sen palabras e con situacións familiares, persoas e obxectos da súa contorna, mentres se lles relatan historias e conversas a partir delas. No segundo ciclo, dende os tres ata os seis anos, os libros ilustrados como os contos populares e de fadas, fábulas e as historias absurdas con finais inesperados son os máis comúns entre a oferta existente. A literatura de tradición oral que máis aparece nesta etapa son as coplas, mitos, lendas, xogos de palabras, roldas e poesía.

No seguinte subapartado amoso o guión froito da reflexión feita que podería guiar ás persoas que teñan en mente deseñar un libro musicado dirixido á infancia. Así, inténtase recoller e expoñer en forma de pregunta os aspectos dos libros musicados infantís sobre os que resulta de interese cavilar e pensar á hora de editar libros musicados que se pretenden publicar para este tipo de destinatariado. As respostas deben valorarse de acordo cos obxectivos de cada traballo.

$\mathrm{Na}$ verdade, todos os criterios que a continuación se expoñen están relacionados, e algúns ítems ou preguntas poderían estar encadrados noutros apartados. Dende logo que os apartados que se recollen son de vital relevancia, pois "é considerable a importancia funcional de elementos estruturadores do texto como son, por exemplo, os organizadores previos, as preguntas, as ilustracións, secuenciación, etc.” (Rodríguez Diéguez, Clemente Linuesa, Roda Salinas, Beltrán de Tena \& Quintero Gallego, 1984, p. 142). Emporiso, recoller e revisar todas as posibilidades é "tarefa suficientemente ampla para constituír por si soa diversos artigos" (p. 142), polo que o contido deste artigo veríase rebordado.

\section{Contido, narración e estrutura}

Que tipo de letra se usa nos textos?

É o título a "carta de presentación" do contido? Pode mellorarse? Como?

É o tema interesante/atraente para a franxa de idade á que vai destinado o libro musicado? Causa impacto o conflito da historia?

Ten sentido/unha estrutura clara a historia que se conta? É claro o desenvolvemento da idea/trama? Hai combinación de tramas? Capta a/s trama/s a atención das persoas ás que vai dirixida?

Dende que perspectiva está contada a historia?

É "plana" a narración dos feitos? É axeitado o estilo de narración para estas idades?

Hai diálogos? Como son? Son monótonos?

Hai linguaxe metafórica ou simbólica? Hai un exceso de carga simbólica?

Son os textos axeitados para ler en voz alta?

Está a linguaxe coidada? É o vocabulario comprensible para estas idades? Úsase linguaxe inclusiva e non sexista?

\section{Personaxes, obxectos e espazos}

De habelos: descríbense claramente? Aparecen nas ilustracións ou só se referencian no texto? (quizais non se precise descrición...) Pódese distinguir o ambiente cultural representado de forma realista?

Son xenuínos? Conectan emocionalmente co destinatariado? Como e a través de que canles?

Os espazos: son urbanos, suburbanos, rurais? Percíbense de forma realista ou permiten a libre imaxinación?

\section{Sentido psicopedagóxico}

Cal é a transcendencia (lección ou aprendizaxe) do texto musicado? Hai unha clara educación en valores, tocando temas transversais? Cales? Como se promoven os valores? Invítase a explorar valores ou son estes predicados sen máis?

Estereotípanse algúns conceptos? Cales e como?

Os contidos inducen á cavilación e ao debate? Ten cabida neles a diversidade?

Constitúe o "problema" da historia (se o houber) un reto? Resólvese dunha forma interesante? Como se vencen os obstáculos (se os houber)?

Hai unha perspectiva inclusiva e non discriminatoria (de roles de xénero, de culturas, de habilidades diversas, etc.) no contido do texto?

Que procesos psicolóxicos estimulamos cos contidos do libro musicado?

Que contidos do currículo da Educación Infantil se traballan con cada texto deste libro musicado?

As consignas (de habelas) están pensadas para que todas as persoas podan participar?

\section{Lóxica pedagóxico-musical}

Como é a prosodia das cancións? Respecta a prosodia da lingua galega?

Os aspectos musicais (interválica, tesitura e altura, tempo, intensidade, melodía, forma, duración, tons, harmonía, etc.) da canción responden ás bases científicas 
que fundamentan o desenvolvemento psicofísico musical do usuariado ao que vai dirixido?

As indicacións de movemento (se as houbera) están adaptadas ás características de desenvolvemento motor da idade á que vai dirixida?

\section{Edición e ilustración}

A portada: Como é a tipografía? É o suficientemente atraente? Por que? É dura o rústica? A ilustración da portada chama a atención do público? Anticipa o contido do libro ou do CD?

As ilustracións: Que material, técnicas, procedementos (debuxo, pintura, collage, etc.) se empregaron? Complementan o texto ou ilustran o que se describe no texto? Cal é o estilo (ilustración primitiva, impresionista, cubista, realista, surrealista, hiperrealista, caricatura, etc.)? Cal é a ambientación? Cales son os aspectos que comunican (cores vivas, suaves, sombrías; ilustracións informativas ou imaxinativas, etc.)? Cal é o equilibrio entre a ilustración e o texto? A ilustración achega información que non se evidencia no texto? Pode dar lugar a equívocos ou paradoxos a interpretación das imaxes?

A tipografía das diferentes partes do libro e CD ten un tamaño suficiente e é lexible?

As páxinas: Están soltas, encadernadas ou aneladas? Cal é a organización das páxinas? Desaprovéitanse os espazos? Como é a diagramación? É a edición fixa? Esfóllase facilmente? É resistente?

Cal é o tipo de papel escollido para a impresión? É o material funxible? Permite ser manipulado?

É o libro moi pesado?

\section{Lingua e, se a houber, tradución}

Respectan os textos a normativa actual da Real Academia Galega: léxico, gramática, etc.?

Hai rima ou vocabulario forzado?

\section{Material audiovisual}

É de fácil manipulación/uso? Complementa o libro? En que senso? Mellora ou axuda na comprensión do libro? Inclúe unha copia dixital do libro?

Cal é o ritmo audiovisual dos contidos? Son os contidos o suficientemente atractivos?

Sobre a música: Capta a música a atención dos e das oíntes? Que instrumentos soan e con que frecuencia? Son facilmente identificables?

Sobre as voces: Como son as voces que interveñen? En que calidade vocal se enmarcan? Como é a articulación? Enténdese o que se relata ou se canta? Coidan as voces un modelo de impostación vocal exemplar?

No caso dos contos con música de fondo, é a duración de cada fragmento musical axeitada para o texto que corresponde ler ou cantar ao mesmo tempo?

\section{Con respecto á avaliación externa}

A produción de materiais didácticos é unha práctica pedagóxica complexa (Viaño, 2013), pois nela entran en xogo o proceso de ensino-aprendizaxe, complicado en si mesmo, con outros "factores que o dotan de significado" (Viaño, 2013, p. 415), como o sistema educativo en que se enmarca, as características do alumnado, o contido, o rol docente, o currículo escolar, o modelo pedagóxico adoptado, etc.
Os libros musicados para infantil en galego conforman un recurso didáctico máis co que educar e/ou instruír, que conxuga literatura e música ao mesmo tempo. Casan cos tempos nos que estamos, onde as diferentes formas de edición se mesturan: neles poden aparecer diferentes linguaxes (musical, escrita, literaria, oral, etc.), imaxes, audios, texturas e olores (por que non?). Estas iniciativas, xunto con outras, veñen dadas do interese na contribución e compromiso coa renovación educativa, que busca fomentar o hábito da lectura achegando ás máis cativas á musica; e ao revés, partir de conceptos máis musicais para aveciñalas á lectura. Son poucos os esforzos realizados nesta liña (Viaño, 2013) e algúns dos que se fan non se publican, co cal permanecen no anonimato ou no coñecemento de contadas privilexiadas.

Tamén é certo que, como comentei ao inicio deste artigo, profesionais da investigación, do ensino, da música ou do teatro aventuráronse a publicar contos musicados ou libros-CD en galego, de diferentes temáticas e con diversos obxectivos, chegando a realizar nalgún caso múltiples concertos didácticos en vivo por diversas vilas de Galicia, enchendo teatros, prazas, bibliotecas, colexios, etc. Estas iniciativas foron moi ben recibidas entre profesionais da infancia, ante a ausencia deste tipo de materiais, cubrindo deste xeito un oco que antes era máis pobre e enriquecendo as propostas, tanto musicais como literarias, e incluso de normalización lingüística.

Agardando que a transferencia se expanda, que estas iniciativas se perpetúen e estes libros musicados se multipliquen, nun futuro próximo precisaremos pasar desta primeira fase de "elaboración de libros musicados" a unha segunda fase de "avaliación de libros musicados", co gallo de velar pola calidade destes. O fin último de todo este proceso é melloralos en todos os sentidos, para que sexan máis competitivos e ofrezan un abano máis amplo de posibilidades, cunhas bases fundamentadas, e atendendo ás necesidades vitais do desenvolvemento psicopedagóxico e musical da idade infantil.

Coa intención de obter unha devolución orientada á mellora ou de publicar un manual de boas prácticas consensuado, máis que de establecer rankings ou clasificacións, perfílanse de seguido os obxectivos, funcións e perfís profesionais das persoas compoñentes e doutros axentes que poderían estar vinculados á creación dun comité avaliador de libros musicados para a infancia. Co apoio nas propostas de Lluch e Chaparro (2007) e Boland (1999) elaborouse unha propia, contextualizada na nosa Comunidade.

\section{O comité avaliador de libros musicados infantís en galego}

O Dicionario da Real Academia Galega define "comité" como un "conxunto de persoas elixidas nunha asemblea para a realización de certas funcións" (Dicionario da RAG, s.d.). Este mesmo dicionario define "avaliar" como "determinar ou considerar o valor de [algo]" ou "valorar o rendemento e dar unha cualificación a [algo]" (Dicionario da RAG, s.d.). O comité, polo tanto, conformaría un espazo de intercambio de coñecementos e experiencias para persoas competentes e/ou expertas en libros musicados 
infantís e en galego. Grazas a esta bagaxe profesional pasada e presente, este comité gozaría co privilexio de contar cunha actualización sobre a oferta editorial e podería contribuír na construción e axuste dos criterios de avaliación dos libros musicados a través dun diálogo permanente con e para o propio grupo de persoas que o integra.

\section{Quen podería facer parte del?}

Atendendo á temática que nos ocupa, poderían formar parte del estudantado avanzado e profesionais con experiencia en áreas como literatura, Educación Infantil, psicoloxía, filoloxía e lingüística -especialmente con sensibilidade de cara ao uso da linguaxe inclusiva e non sexista-, tradución, música e/ou pedagoxía musical, promoción da lectura, ilustración, deseño gráfico ou edición.

\section{Obxectivos e funcións hipotéticas do comité}

Poderían concretarse en:

Realizar encontros para o desempeño das tarefas que aquí se propoñen, por exemplo, mensualmente.

Construír e axustar os criterios de avaliación dos libros musicados galegos e en galego a través dun diálogo aberto á escoita e discusión.

Desenvolver un protocolo de avaliación de libros musicados, suxeito á mellora e renovación periódica.

Avaliar libros musicados a través do protocolo de avaliación e ofrecer asesoramento de cara á mellora.

Discutir a calidade dos libros musicados que cheguen ao comité e emitir xuízos de mellora a cada editorial e/ou autor ou autora sobre as súas propostas.

Actualizar a oferta editorial de libros musicados en Galicia e en galego.

Realizar unha base de datos completa dos libros musicados publicados en galego.

Tratar de dar respostas profesionais e asesoramento a persoas que traballan na formación de lectores e lectoras.

Deseñar e desenvolver plans de formación continua para persoal docente e de biblioteca, e outros colectivos interesados na temática.

Orientación a persoal bibliotecario e de centros educativos, entre outros espazos -como o da familia ou os ámbitos laborais-, sobre os libros musicados dispoñibles no mercado máis adecuados, segundo o caso.

Elaborar documentos de boas prácticas no deseño de libros musicados e sobre a utilización pedagóxica e uso debido destes.

Axudar na planificación dos investimentos públicos en libros musicados para bibliotecas.

Publicar listaxes dos libros musicados recomendados e recensións en revistas, libros e páxinas web, cos debidos argumentos.

Asesorar á Administración na formulación de plans e programas de fomento da lectura.

Impulsar e desenvolver investigacións que axuden a mellorar a calidade dos libros musicados en Galicia e en galego.

Propoñer e organizar encontros, congresos e xornadas que velen pola transferencia da información, de experiencias, e ao fin e ao cabo, de coñecemento.

Dinamizar accións e obradoiros varios en relación á lectura, a través da organización de actividades ou colaboración con centros educativos, bibliotecas, asociacións e/ou outros organismos.

\section{Outros axentes}

Entendendo que as e os profesionais que integrarían este comité desempeñan o seu traballo na súa institución de procedencia, cabería pensar no mester dun persoal de apoio ao comité que axudara na concreción dos obxectivos que veñen de ser expostos. Precisaríase, polo tanto dun organismo responsable coordinador das accións.

Concibindo as bibliotecas máis alá dos cometidos sumamente coñecidos atribuídos a estas, na liña de Novoa e Sampedro (2013), este persoal de apoio podería ter como campamento base unha biblioteca pública galega ou, por que non, un museo ou un centro sociocultural. As funcións deste organismo poderían ser:

Crear e actualizar a páxina web do comité.

Recibir os libros musicados por parte de distribuidoras e editoras, co interese de que sexan avaliados.

Rexistrar os libros entrantes e repartilos entre o comité. Organizar as reunións e os materiais e espazos que puideran facer falta nestes encontros.

Recoller os informes de avaliación do comité avaliador dos libros musicados avaliados e clasificalos atendendo a calidade, xénero, descritores, nivel de lectura (atendendo ao nivel de desenvolvemento das crianzas ás que vai dirixido), etc.

Facer chegar a distribuidoras, editoras e autores e autoras, a xeito de feedback, os informes da comisión avaliadora.

Apoiar e facilitar as dilixencias precisas para o bo funcionamento e organización das actividades organizadas polo comité e outras institucións.

\section{Discusión e consideracións finais}

Os libros (en xeral, e non só os musicados), de acordo coa literatura consultada, deberán ir adaptando o seu formato e contido aos tempos nos que se produzan (Moyano, 2009), sen esquecer o factor "contextualizador", que debe tamén ser tido en conta, de acordo cos argumentos de Vicente (2009).

Estas circunstancias unidas a outras non menos importantes como o contido, o sentido psicopedagóxico, a edición ou a ilustración serían puntos de inflexión nos cales poder basear a elaboración dun protocolo de avaliación da calidade dos libros musicados en galego realizados na Comunidade Autónoma de Galicia. Este traballo, en definitiva, abre unha vía de debate sobre a calidade, a avaliación e adaptación ás novas formas de editar do momento histórico que nos tocou vivir, absorbido polo imperativo tecnolóxico, que nos está a desafiar e que nos obriga a actualizar constantemente.

Nestes tempos de cambio tecnolóxico nos que vivimos, nos que conviven diferentes soportes que apoian os procesos de ensino-aprendizaxe; tempos abertos á creatividade, xunto cos insólitos xeitos de edición, fannos chegar frescas canles de expresión. Mais, por veces, todo isto fai que esquezamos o básico. Con elo, este texto ofrece un punto de partida para a elaboración duns estándares que poderían chegar a ser concretados nun futuro. Estes estándares conformarían unha 
orientación sobre os aspectos que se poderían ter en conta para mellorar a calidade dos libros musicados que se elaboran, resultando máis axustados ás realidades e necesidades do destinatariado, a expensas da ollada crítica de profesionais da educación e da sociedade en xeral.

Como proposta de futuro, cabería discutir o que aquí se expón con algún grupo de investigación ou organismo ligado a estes temas, para avaliar a viabilidade da posta en marcha das proposicións que aquí se recollen, especialmente en termos de financiamento e mantemento.

Dende logo que este texto a xeito de chamada de atención paréceme necesario, pois estou convencida de que os libros musicados axudan a que as crianzas aproveiten a súa intelixencia emocional e afectiva. Por iso, mimando máis de preto os elementos que concirnen ao libro musicado en si, o crecemento intelectual das nosas pequenas e pequenos verase favorecido (Herrera, 2006).

\section{Referencias}

Boland, E. (1999). Hojas sueltas. Sobre promoción de la lectura y bibliotecas para niños. Carrera de Bibliotecología del Instituto Superior de Formación Docente y Técnica $\mathrm{N}^{\circ}$ 8, 4. La Plata, Provincia de Buenos Aires, Argentina. http://www.imaginaria.com.ar/00/8/boland.htm

Diccionario da Real Academia Galega (s.d.). http://academia.gal/dicionario

Herrera Ruíz, S. (2006). Cartas que veñen e van. A Coruña: Primerapersona.

Lluch, G. \& Chaparro, J. (2007). La evaluación de los libros para niños y jóvenes. Una investigación sobre la experiencia de FUNDALECTURA. Revista OCNOS, 3 ,

103-119.

https://www.revista.uclm.es/index.php/ocnos/article/v iew/ocnos_2007.03.07

Moyano, J. (2009). El sector del libro de texto en España: Análisis de la situación presente y perspectivas de futuro. En J. Rodríguez Rodríguez, M. Horsley, \& S. V. Knudsen (eds.), 10th International Conference on Textbooks and Educational Media. Local, National and Transnational Identities in Textbooks and Educational Media (pp. 47-49). Santiago de Compostela: IARTEM. https://es.scribd.com/document/60088971/X-Conferen ce-Textbooks-IARTEM-155x235-HD

Novoa, C. \& Sampedro, P. (2013). O papel das bibliotecas escolares na elaboración dos materiais didácticos. En M. M. Castro Rodríguez, X. Rodríguez Rodríguez, \& M. H. Zapico Barbeito (coords.), Materiais didácticos e experiencias educativas innovadoras (pp. 47-58). Noia: Toxosoutos.

Rodríguez Diéguez, J. L., Clemente Linuesa, M., Roda Salinas, F. J., Beltrán de Tena, R., \& Quintero Gallego, A. (1984). Evaluación de textos escolares. Enseñanza and Teaching, 2, 139-152. https://gredos.usal.es/jspui/handle/10366/69181

Viaño García, M. (2013). "O rodaballo con botas", conto musical. En M. M. Castro Rodríguez, X. Rodríguez
Rodríguez, \& M. H. Zapico Barbeito (coords.), Materiais didácticos e experiencias educativas innovadoras (pp. 415-426). Noia: Toxosoutos.

Vicente Álvarez, R. M. (2009). Music materials in early childhood education: A descriptive analysis of their use by teachers of early childhood education and music in the city of Santiago de Compostela. En J. Rodríguez Rodríguez, M. Horsley, \& S. V. Knudsen (eds.), 10th International Conference on Textbooks and Educational Media. Local, National and Transnational Identities in Textbooks and Educational Media (pp. 392-402). Santiago de Compostela: IARTEM. https://es.scribd.com/document/60088971/X-Conferen ce-Textbooks-IARTEM-155x235-HD

\section{Agradecimientos}

A autora desfruta dun contrato predoutoral financiado polo Ministerio de Economía e Competitividade Español e é investigadora e docente en formación e perfeccionamento dentro do grupo de investigación Grupo Interuniversitario de Estudios (GIE-USC). 